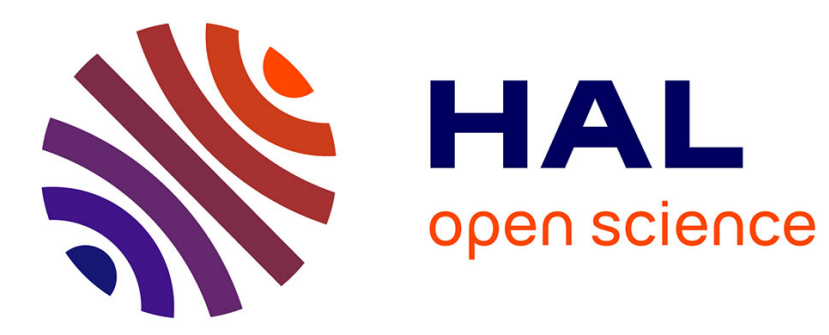

\title{
Lignin-graphene oxide inks for 3D printing of graphitic materials with tunable density
}

Julien Roman, Wilfrid Neri, Vanessa Fierro, Alain Celzard, Ahmed Bentaleb, Isabelle Ly, Jing Zhong, Alain Derré, Philippe Poulin

\section{- To cite this version:}

Julien Roman, Wilfrid Neri, Vanessa Fierro, Alain Celzard, Ahmed Bentaleb, et al.. Lignin-graphene oxide inks for 3D printing of graphitic materials with tunable density. Nano Today, 2020, 33, pp.100881. 10.1016/j.nantod.2020.100881 . hal-03041952

\section{HAL Id: hal-03041952 \\ https://hal.univ-lorraine.fr/hal-03041952}

Submitted on 18 Dec 2020

HAL is a multi-disciplinary open access archive for the deposit and dissemination of scientific research documents, whether they are published or not. The documents may come from teaching and research institutions in France or abroad, or from public or private research centers.
L'archive ouverte pluridisciplinaire HAL, est destinée au dépôt et à la diffusion de documents scientifiques de niveau recherche, publiés ou non, émanant des établissements d'enseignement et de recherche français ou étrangers, des laboratoires publics ou privés. 


\title{
Lignin-Graphene Oxide Inks for 3D Printing of Graphitic Materials with Tunable Density
}

Julien Roman ${ }^{\mathrm{a}}$, Wilfrid Neri ${ }^{\mathrm{a}}$, Vanessa Fierro ${ }^{\mathrm{b}}$, Alain Celzard ${ }^{\mathrm{b}}$, Ahmed Bentaleb $^{\mathrm{a}}$, Isabelle Ly ${ }^{\mathrm{a}}$, Jing Zhong ${ }^{\mathrm{c}}$, Alain Derré ${ }^{\mathrm{a}}$, Philippe Poulin ${ }^{\mathrm{a},{ }^{*}}$

${ }^{\text {a }}$ Université de Bordeaux, Centre de Recherche Paul Pascal (CRPP), UMR 5031, Avenue Albert Schweitzer, 33600 Pessac, France.

${ }^{\mathrm{b}}$ Université de Lorraine, Institut Jean Lamour (IJL) UMR 7198 ENSTIB, 21 rue Ph. Seguin, 88000 Epinal, France.

${ }^{c}$ Key Lab of Structure Dynamic Behavior and Control (Harbin Institute of Technology), Ministry of Education, Harbin 150090, PR China.

\begin{abstract}
Graphitic structures, unlike polymers and metals, cannot be directly printed in 3D. We demonstrate here that graphitic structures can be shaped in 3D by using direct-ink writing (DIW) of lignin-graphene oxide solutions that are then dried and carbonized. Lignin is a promising precursor for the elaboration of bio-based carbon materials because of its low cost, natural availability and high carbon content. The rheology of the inks is controlled by the presence of graphene oxide (GO) in order to make the solutions viscoelastic and printable. The GO flakes are found to align during ink extrusion. This behavior is understood by considering the applied extrusion shear stress and the yield stress of the inks. By adjusting the relative fraction of GO and lignin, it is possible to change the density, the graphitic order, and thus the electrical and mechanical properties of the printed materials. In particular, GO promotes not only graphitic order but also porosity. By contrast, high amounts of lignin allow preparing denser but less ordered carbon structures. The possibility to vary density and properties offers an opportunity for the development of graphitic 3D materials with tunable properties.
\end{abstract}

*Corresponding author. Tel: (+33) 556845649. E-mail: philippe.poulin@crpp.cnrs.fr (Philippe Poulin) 


\section{Introduction}

Graphite is an ubiquitous carbon allotrope with countless applications [1-3]. These applications are based on the unique properties of graphite, including chemical stability, electrical conductivity and mechanical stiffness [4-6]. Graphitic materials can be used under various forms, from fibers for reinforcing composites to porous aerogels and hard carbons for electrodes of supercapacitors [7,8] and batteries [9-11]. Shaping graphitic structures is an important challenge to further broaden the range of applications of such materials $[12,13]$. Implementing current 3D printing technologies to process graphitic materials is particularly appealing [14,15]. Additive manufacturing allows shapes not doable by conventional machining and avoids the waste of precursor material. Unfortunately, graphitic materials, unlike polymers and metals for example, cannot be easily melted or solubilized for processing. Generally, carbon materials are made from precursors which are further carbonized by a thermal treatment $[16,17]$. In this context, successful achievements of 3Dprinted carbonized materials have been recently reported using graphene oxide (GO) as precursor [18-21]. GO has a high carbon content and can be dissolved in water to form viscoelastic inks suitable for printing using the Direct-Ink Writing (DIW) approach [22]. The latter consists in extruding a shear-thinning ink whose yield stress is high enough so that the printed structure does not collapse after extrusion $[23,24]$. The shear-thinning behavior allows extrusion at a reasonable pressure. In addition, highly concentrated GO solutions show a liquid crystal behavior, opening perspectives for controlling the alignment of GO flakes during extrusion. [25]

This approach has allowed the realization of graphene microlattices [18,26]. Nevertheless, the printed structures are in the form of highly porous and mechanically weak carbon aerogels $[8,26]$. We report in this work an approach to make denser structures based on printed GO. This approach consists in adding alkali lignin [27], a lignin derivative, to GO inks. Lignin is an abundant bio-sourced polymer which has a high carbon content [28,29]. It cannot be used alone to form viscoelastic inks [30]. Herein, we show its compatibility with GO solutions that remain monophasic and viscoelastic. Unlike previous studies in which lignin was mixed with other gelling agents [30-32], lignin is here mixed with GO to ensure a high carbon yield upon carbonization. The density and graphitic structure of the carbon materials can be finely tuned by varying the relative fractions of GO and lignin in the ink. We show in particular that a high fraction of lignin allows preparing denser, but less organized, structures. By contrast, a high amount of GO leads to well-structured, but more porous, carbon. As a result, properties such 
as electrical conductivity or mechanical stiffness can also be tuned by controlling the composition of the initial ink. Compromises of structuration and densification allow in particular defining optimized formulations for enhanced electrical conductivity. The present results are discussed based on rheological, physical and structural characterizations of the investigated materials. They provide opportunities to make novel 3D graphitic structures with tunable properties.

\section{Experimental Section}

\subsection{Materials}

Water-soluble alkali lignin powder was purchased from Sigma-Aldrich under the trade name of "lignin alkali low sulfonate content". This alkali lignin is also known as Kraft lignin with an average molecular weight of 10,000 g.mol ${ }^{-1}$ and a low sulfur content (4 wt.\%). Aqueous GO solution at 0.4 wt.\% was purchased from Graphenea (Spain). It contains GO flakes with a lateral size of $0.6-1.1 \mu \mathrm{m}$ (according to datasheet). Sonication and centrifugation (1400 g, 20 min) steps have been performed to separate and remove aggregated GO flakes from the solution. Alkali lignin was used as received without further purification. For simplicity reason, alkali lignin will be referred in the following parts as "lignin".

\subsection{Preparation of lignin-GO inks}

Different lignin-GO inks with various GO/lignin mass ratios were prepared as follows. The GO solution was concentrated by ultracentrifugation $(200000 \mathrm{~g}, 1 \mathrm{~h})$ to obtain GO-based printable ink concentrated at 8 wt.\%. An aqueous lignin solution was prepared with a concentration of $30 \mathrm{wt} . \%$. Fixed amounts of this aqueous lignin solution were added to the GO ink to obtain aqueous lignin-GO inks concentrated at $8 \mathrm{wt}$ \% with $\mathrm{GO} /$ lignin mass ratios of $100 / 0,70 / 30,50 / 50,30 / 70,15 / 85$ and $0 / 100$. The lignin-GO inks were mixed under vortex stirring for $10 \mathrm{~min}$ and then sonicated for $5 \mathrm{~min}$ to disperse residual aggregates.

\subsection{Ink rheology}

The rheological properties of the inks were characterized using an AR 2000 rheometer (TA Instruments) with a $40 \mathrm{~mm}$ cone-plate geometry and a $50 \mu \mathrm{m}$ gap. All measurements were preceded by a constant shear rate of $1 \mathrm{~s}^{-1}$ for $1 \mathrm{~min}$, followed by a $10 \mathrm{~min}$ relaxation period to recover the ink structure. Dynamic measurements were performed to record the apparent viscosity at $25^{\circ} \mathrm{C}$ in the frequency range of $10^{-1}$ to $10^{2} \mathrm{~Hz}$. A stress scan from $10^{0}$ to $10^{4} \mathrm{~Pa}$ at a constant frequency of $1 \mathrm{~Hz}$ was carried out to record the variations of storage modulus $\left(G^{\prime}\right)$ 
and loss modulus $\left(G^{\prime \prime}\right)$ as a function of the scanning stress. The ink yield stress $\left(\tau_{y}\right)$ was defined as the stress for which storage modulus and loss modulus intersect ( $\left.G^{\prime}=G^{\prime \prime}\right)$. An aqueous solvent trap was used in all experiments to reduce water evaporation effects.

\section{4. $3 D$ Printing}

GO-lignin inks were used to fabricate cylindrical hollow structures using a modified commercial 3D printer (Prusa i3). The original extrusion head was replaced by a powered fluid injector controlled by the initial 3D-printer engine in order to provide the appropriate pressure to extrude the ink through the nozzle. The ink was loaded into a $5 \mathrm{~mL}$ syringe attached by a luer lock to a pressure sensor (Flowplus16, Viscotec) in order to evaluate the pressure applied to the ink during the printing process. The $350 \mu \mathrm{m}$-diameter printing nozzle was luer locked to the end of the pressure sensor. The inks were printed on glass substrates in air at an applied pressure of 1-4 bar at a speed of $10 \mathrm{~mm} . \mathrm{s}^{-1}$. After printing, the obtained structures were frozen in liquid nitrogen and subsequently freeze-dried for $24 \mathrm{~h}$ to obtain composite GO-lignin 3D structures. The thermally dried and reduced 3D structures were directly obtained after printing, by thermal treatment in air at $250{ }^{\circ} \mathrm{C}$ in a muffle furnace

(Nabertherm $\mathrm{GmbH}$ ) heated at $2.5^{\circ} \mathrm{C} \cdot \mathrm{min}^{-1}$. Subsequently, the reduced structures were annealed under argon by heating in a tubular furnace at $5^{\circ} \mathrm{C} \cdot \mathrm{min}^{-1}$ to $1000^{\circ} \mathrm{C}$ and held for $1 \mathrm{~h}$ at $1000^{\circ} \mathrm{C}$. The thermal treatment converted the $3 \mathrm{D}$-printed lignin-GO composite structures into 3D-printed bio-based carbon materials with a graphitic structure (Fig. 1). Note that $1000^{\circ} \mathrm{C}$ is not sufficient to form pure and defect free graphite. Highly graphitized materials are generally formed at much higher temperatures of about $3000^{\circ} \mathrm{C}$.

\subsection{Characterization}

The morphology of the printed structures was observed by optical camera and scanning electron microscopy (SEM, Hitachi S4500). The thermal stability of the printed structures was evaluated by thermogravimetric analysis (TGA) (TGA 5500IR, TA Instruments). Around 10 $\mathrm{mg}$ of sample was loaded into an alumina pan and heated from $30^{\circ} \mathrm{C}$ to $250^{\circ} \mathrm{C}$ at $2.5^{\circ} \mathrm{C} \cdot \mathrm{min}^{-1}$ under air, corresponding to the stage of thermal drying, then from $250^{\circ} \mathrm{C}$ to $1000^{\circ} \mathrm{C}$ at $5^{\circ} \mathrm{C} \cdot \mathrm{min}^{-1}$ under argon, corresponding to the stage of carbonization. The TGA measurements give access to the final carbon yield defined as the weight percent of char after the carbonization process. The carbon microstructure was analyzed using X-ray diffraction (XRD) and Raman spectroscopy. The XRD patterns were acquired using a Rigaku Nanoviewer XRF microsource generator (MicroMax 007HF) at a wavelength of $1.54 \AA$, with 
a 1200-W rotating anode coupled to a confocal Max-FluxH Osmic mirror (Applied Rigaku Technologies, Austin, USA) and a MAR345 image plate detector (MAR Research, Norderstedt, Germany). The azimuthal integrations of the 2D patterns were processed using Foxtrot software. The patterns were corrected from air scattering and backgrounded by subtracting a sample-free diffraction pattern from the raw data. The Raman spectra were recorded using a Horiba Jobin-Yvon Xplora microscope equipped with a cooled Andor CCD detector, using an excitation wavelength of $534 \mathrm{~nm}$, a laser spot size of $\sim 1 \mu \mathrm{m}$, and an Olympus 50× LWD objective. The electrical conductivity of the carbonized structures was measured by the two-point method using a Keithley 2000 multimeter. To ensure good contact with the electrode, a thin layer of conductive silver paste was used. The electrical conductivity $\kappa\left({\left.\mathrm{S} . \mathrm{cm}^{-1}\right)}^{-}\right.$was calculated as:

$$
\kappa=\frac{L}{A R}
$$

where $R$ is the measured electrical resistance $(\Omega), A$ is the cross-sectional area $\left(\mathrm{cm}^{2}\right)$ and $L$ is the distance between the two probes $(\mathrm{cm})$. The compressive mechanical properties were measured using a Zwick Z2S testing machine. The 3D-printed cylinders were compressed at a rate of $6 \mathrm{~mm} \cdot \mathrm{min}^{-1}$ to record the force as a function of strain (\%). The measured force was converted into stress $(\mathrm{Pa})$ calculated from: Stress $(\mathrm{Pa})=$ Force $(\mathrm{N}) /$ Cross Section $\left(\mathrm{cm}^{2}\right)$. The Young's modulus was calculated from the initial slope of the stress-strain curves. The compressive strength at break was evaluated at the point where a $10 \%$ drop of stress occurred. The skeletal density of the printed carbon structure was determined using a series of density floats solutions. Aqueous cesium formate solutions were prepared with densities ranging from 1.4 to $2 \mathrm{~g} . \mathrm{cm}^{-3}$ in increments of $0.05 \mathrm{~g} . \mathrm{cm}^{-3}$. The printed carbon structures were degassed under at $250{ }^{\circ} \mathrm{C}$ under vacuum, then immersed in the cesium formate solutions and allowed to settle for $24 \mathrm{~h}$. The determination of density is based on the solution in which the carbonized structure sunk as opposed to the next denser solution where it floated. The bulk density was calculated from the measured mass and volume of each sample. The percentage of porosity was assessed by comparing the geometric density and skeletal density of each sample. The textural properties of the 3D-printed carbon materials were obtained from nitrogen adsorption at $-196^{\circ} \mathrm{C}$ and from carbon dioxide adsorption at $0^{\circ} \mathrm{C}$ using a Micromeritics 3-flex automatic adsorption apparatus. Samples of mass $\sim 0.1 \mathrm{~g}$ were outgassed under vacuum at $200^{\circ} \mathrm{C}$ until the pressure stabilized around $0.2-0.4 \mathrm{mPa}$ for more than $24 \mathrm{~h}$ prior to any adsorption measurement. 


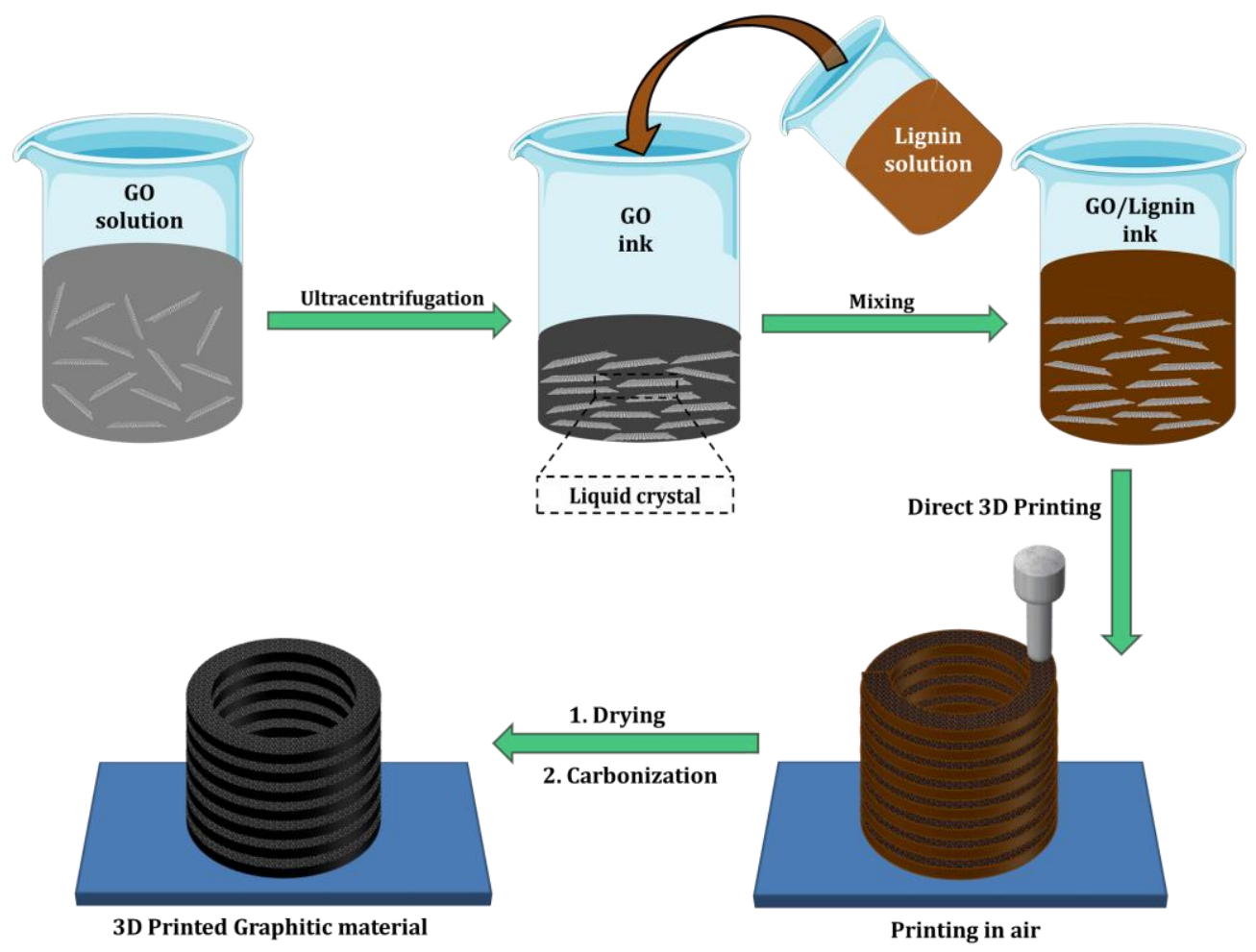

Fig 1. Schematic illustration of the fabrication strategy for 3D-printed lignin-GO-based carbon materials.

\section{Results and Discussion}

\subsection{D Printing and Rheology of Lignin-GO Inks}

The fabrication of graphitic 3D-printed carbon materials by the direct ink writing (DIW) process requires the development of printable lignin-GO composite inks (Fig. 1). The inks used for this approach must have a high viscosity with a shear-thinning behavior to ensure extrusion, and a sufficiently high storage modulus $\left(G^{\prime}\right)$ to recover a solid-like response in order to obtain a self-supporting printed structure [24,33]. The preservation of the filament shape during DIW is controlled by the high yield stress $\left(\tau_{y}\right)$ of the inks [23]. Highly concentrated GO aqueous solutions were used to ensure the rheological criteria for the DIW $[18,26]$. Lignin solution was added to these GO solutions to obtain lignin-GO inks (Fig. 1).

Accurate control of the rheological behavior of lignin-GO inks is necessary to ensure 3D printing of uniform and self-supporting structures (Fig. 2). As shown in Fig. 2.a, the viscosities of pure GO and lignin-GO inks decrease with shear rate increasing. Pure lignin solutions instead exhibit Newtonian behavior. The Newtonian behavior and the low viscosity of the pure lignin solution are not suitable for DIW. The viscosity of lignin-GO inks increases 
with the amount of GO. It is one order of magnitude higher for pure GO ink compared to the lignin-GO ink with a GO/lignin ratio of 50/50. The rheological behavior of lignin-GO inks is determined by the GO concentration. High GO concentrations afford printability [18,34]. Oscillatory measurements allow measuring the storage $\left(G^{\prime}\right)$ and loss $\left(G^{\prime \prime}\right)$ moduli (Fig. 2.b). Pure GO ink and lignin-GO inks show the same viscoelastic behavior. At low shear stress, $G$ ' and $G^{\prime \prime}$ are constant with $G^{\prime}>G^{\prime}$, which corresponds to a solid-like behavior [23]. The large difference, of about one order of magnitude between $G^{\prime}$ and $G$ ', enables stable structures to be made after the extrusion process [22]. At higher shear stress, the inks can flow above a dynamic yield stress $\tau_{y}$ defined as the stress at which $G^{\prime}=G^{\prime \prime}$.

The yield stress as a function of the GO fraction is shown in Fig. 2.c. $\tau_{y}$ increases from 398 to $4050 \mathrm{~Pa}$ with the GO content, and is thus the highest for the pure GO ink. The inks are expected to undergo a liquid-type shear flow if they are extruded at a shear stress greater than the yield stress. Under these conditions, flakes and nematic domains should align in response to shear [35]. By contrast, if the extrusion shear stress falls below the yield stress, the material is expected to display a plug-flow type behavior. In these conditions, the particles are not expected to orient because of the constant velocity in this flow regime [25,35]. To clarify the operating conditions, the radial shear stress $(\tau)$ inside the extrusion head was estimated using the following equation [35]

$$
\tau=\frac{\Delta P}{2 L} r
$$

where $\Delta P$ is the pressure applied to the ink in the nozzle, and $r$ and $L$ are the radius and the length of the nozzle, respectively. Here $r=175 \mu \mathrm{m}$ and $L=3 \mathrm{~mm}$. $P$ was evaluated with the pressure sensor. $P$ increases from $5 \times 10^{4} \mathrm{~Pa}$ to $2.25 \times 10^{5} \mathrm{~Pa}$ with the GO fraction. The corresponding shear stress upon extrusion has been reported and compared to the yield stress of the inks (dotted line in Fig. 2.c). For each ink, the extrusion shear stress is higher than the yield stress. Thus, the GO flakes should be aligned with their c-axis perpendicular to the filament direction (Fig. 2.d). 

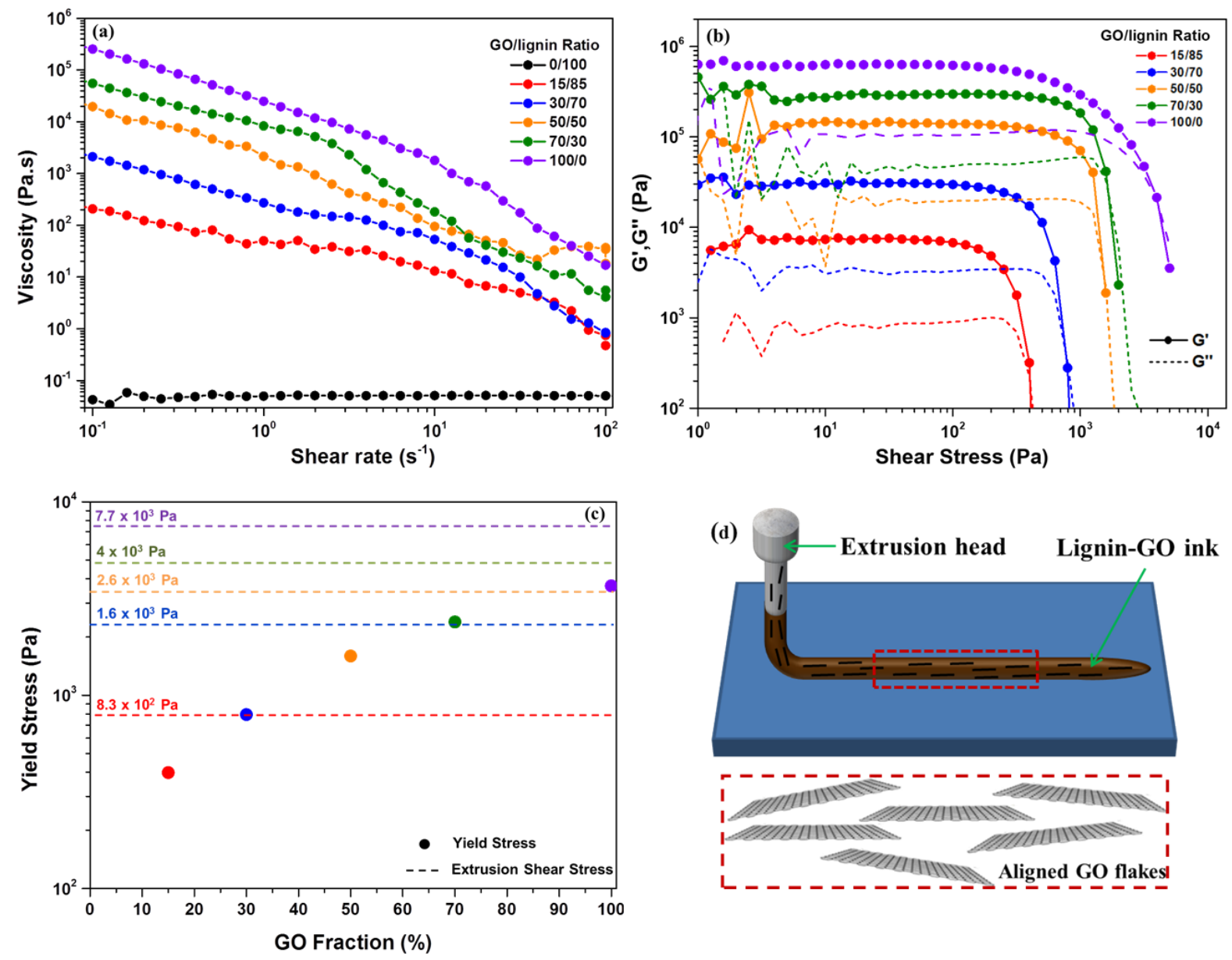

Fig 2. Rheological properties under (a) shear and (b) oscillations (frequency $=1 \mathrm{~Hz}$ ) of ligninGO aqueous inks concentrated at 8 wt.\% with GO/lignin weight ratios of 100/0, 70/30, 50/50, 30/70, 15/85 and 0/100. (c) Shear yield stress of lignin-GO inks as a function of GO fraction (the dotted lines indicate the transition from liquid to plug flow regime). (d) Schematic representation of the alignment of GO flakes during extrusion and after deposition.

\subsection{Morphology of the Lignin-GO 3D-Printed Structures}

Freestanding 3D hollow cylinders were printed with a filament layer of $400 \mu \mathrm{m}$, an outer diameter of $12 \mathrm{~mm}$ and a height of $10 \mathrm{~mm}$ (Fig. 3). The effect of the thermal treatment on a 3D-printed structure with a GO/lignin ratio of 30/70 was evaluated by optical and SEM imaging (Fig. 3.a.c.d). The macroscopic cylinder integrity is preserved after freeze drying, thermal drying and carbonization (Fig. 3.a). After thermal treatment, the color of the samples turned from bright black to brown after drying and from brown to mate black after carbonization. The samples tend to shrink linearly by 5 to $10 \%$ after carbonization. The microstructure is also affected by the drying treatment. SEM images of the freeze-dried sample show large and aligned pores (Fig. 3.c.d-1). The structuration corresponds to a porous 
alveolar microstructure with the walls of the pores made of aligned and stacked GO flakes [36,37]. SEM images of the reduced and carbonized samples show that the preferential orientation of the GO flakes is maintained after the heat treatment (Fig. 3.c.d-3). However, pores of the alveolar structures of the freeze-dried and thermally-dried samples tend to shrink after carbonization. This phenomenon results from the elimination of oxygen and hydrogen during thermal reduction [17], as well as from the evolution of volatile matters from the lignin undergoing carbonization. It is associated with a reduction in the distance between graphene layers $[18,21,38]$.

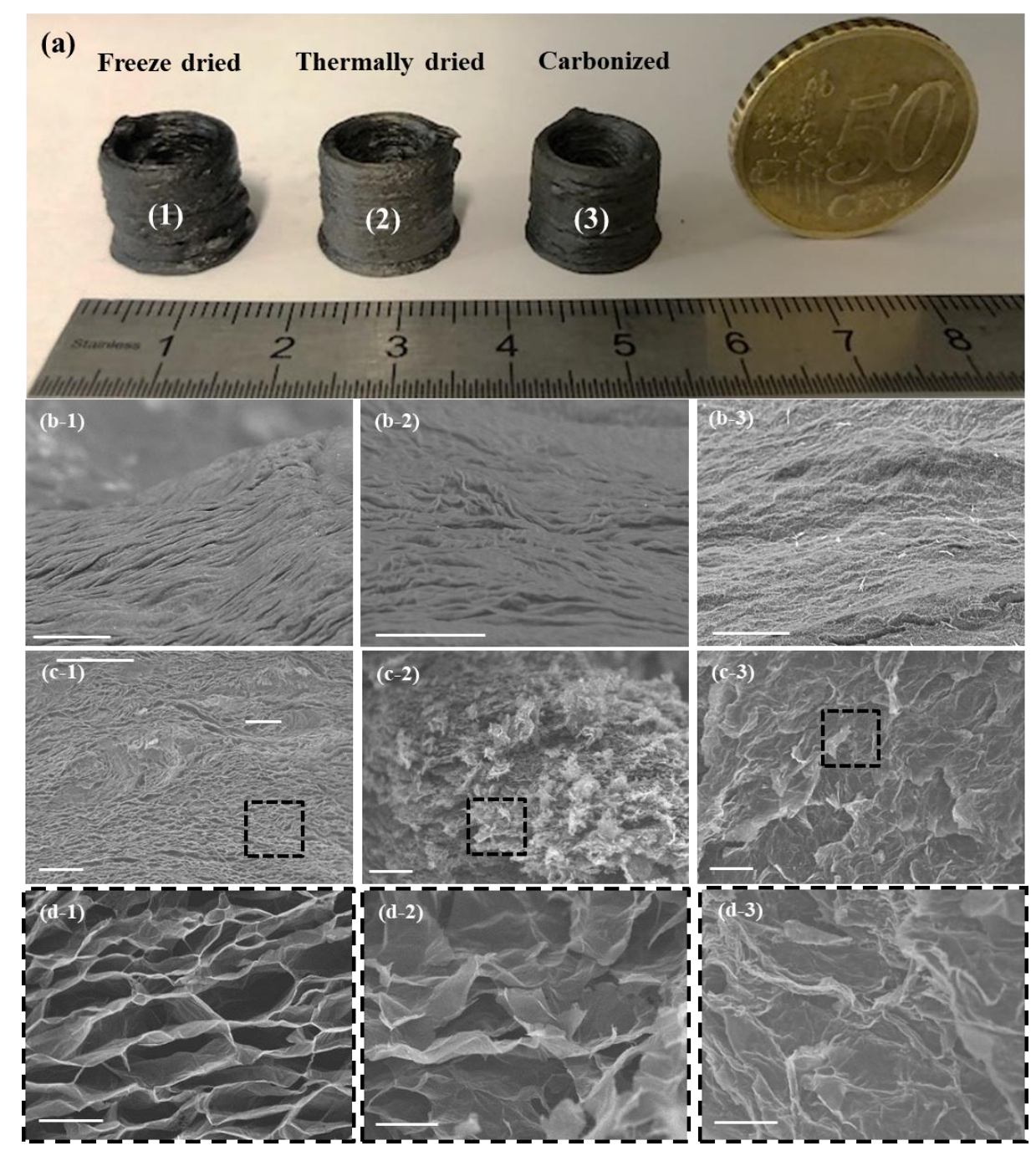

Fig 3. Morphology and structure of 3D-printed structures from lignin-GO ink with a $\mathrm{GO} /$ lignin ratio of 30/70, at different processing steps. (a) Images of 3D-printed structures: (1) freeze-dried, (2) thermally-dried and reduced at $250^{\circ} \mathrm{C}$ in air, (3) carbonized at $1000^{\circ} \mathrm{C}$ under inert atmosphere. SEM images of (b) the surface, (c-d) the microstructure for the 3D-printed cylinders (1) freeze-dried, (2) reduced, (3) carbonized. Scale bars: (b) $200 \mu \mathrm{m}$, (c) $50 \mu \mathrm{m}$, (d) $10 \mu \mathrm{m}$. 


\subsection{Thermal Degradation of Lignin-GO 3D-Printed Structures}

The thermal degradation behavior of the lignin-GO 3D-printed structures was evaluated using TGA (Fig. 4). Thermal stabilization in air was included in the TGA measurement to evaluate the mass loss of the sample after drying. The thermogram of the pure GO sample shows a massive weight loss of $40 \mathrm{wt} . \%$ during drying. It is related to the reduction of GO with the elimination of oxygen groups and the reorganization of the aromatic structure [38]. The presence of lignin in the 3D-printed structures significantly increases the final carbon yield at $1000^{\circ} \mathrm{C}$. The char formation is indeed multiplied by five when comparing the pure GO and samples with a GO/lignin ratio of $15 / 85$. The main difference comes from the weight loss that occurs during the drying process below $250^{\circ} \mathrm{C}$. The treatment at this temperature corresponds in fact to the stabilization step usually performed for lignin-based materials in order to improve the carbon yield and to avoid the melting of the system [28,39]. Chemical reactions such as crosslinking of lignin molecules on the one hand, and lignin and GO on the other hand, increase stability against thermal degradation [40,41]. The addition of lignin to GObased 3D-printed structures thus allows a significant improvement of carbon yield.

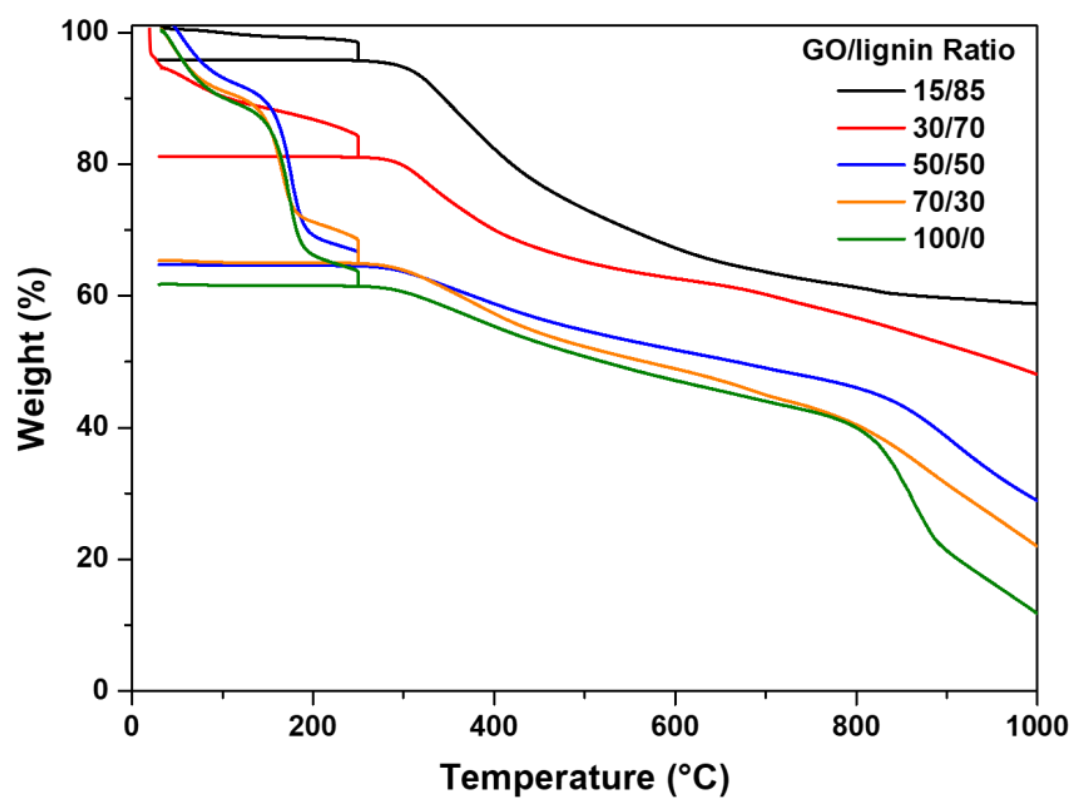

Fig 4. TGA of 3D-printed structures of various GO/lignin ratios, including thermal drying under air up to $250^{\circ} \mathrm{C}$, followed by pyrolysis up to $1000^{\circ} \mathrm{C}$ under argon.

\subsection{Microstructural Properties of the Carbonized 3D-Printed Lignin-GO Structures}

Raman spectroscopy and XRD analysis were performed to characterize the microstructure of the carbonized 3D-printed structures as a function of the GO/lignin ratio (Fig. 5). All Raman 
spectra show the three characteristic bands of pyrolyzed carbon materials around 1350, 1580 and $2700 \mathrm{~cm}^{-1}$. They correspond respectively to the D-band, due to in-plane defects in the $\mathrm{sp}^{2}$ network, the G-band due to the graphitic structure, and the 2D-band giving information on the stacking order along the c-axis (Fig. 5.a).
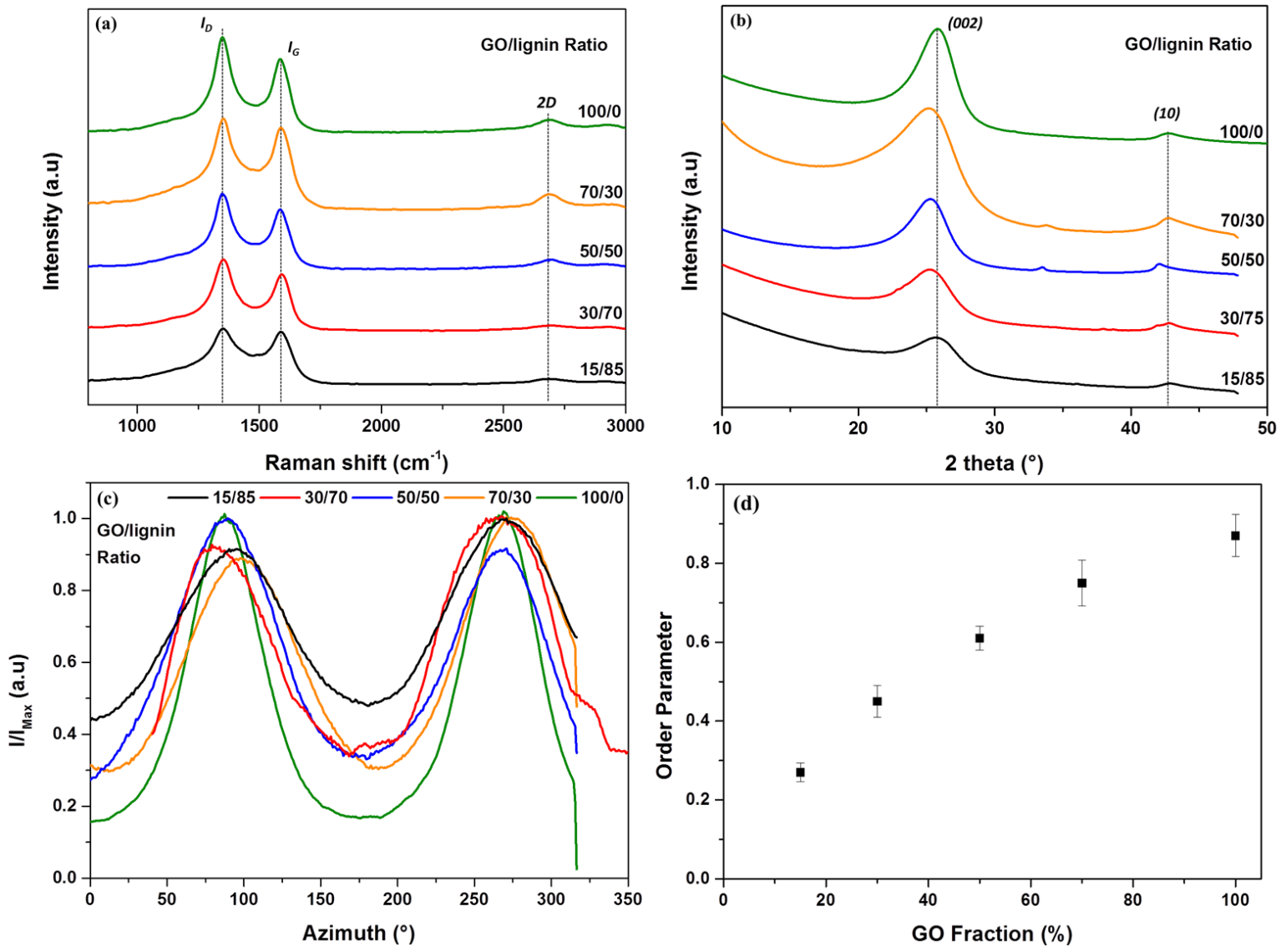

Fig 5. (a) Raman spectra, (b) XRD patterns, (c) normalized 2D-WAXS azimuthal intensity distributions of the (002) reflection, and (d) order parameter of the carbonized 3D-printed structures for various initial GO/lignin ratios.

The presence of two broad $\mathrm{G}$ and $\mathrm{D}$ bands, and a low-intensity 2D band, is typical of pyrolyzed graphene oxide [42]. The peak height of both D and G bands were evaluated to calculate the $I_{D} / I_{G}$ ratio (Table 1). It increases from 1.03 for materials of GO/lignin ratio of 15/85 to 1.41 for pure GO-based materials. This evolution can be related to the formation of nanocrystalline and disordered graphitic domains due to the clustering of aromatic rings present in the lignin molecules, and to the increase of the initial GO quantity $[42,43]$. This transformation also results in the decrease of the width of the bands D and G, as well as in the increase of the $2 \mathrm{D}$ band when the fraction of GO increases. The crystallite lateral size $L_{a}$ was evaluated according to the theory of Ferrari and Robertson [44]. The values are reported in 
Table 1. $L_{a}$ increases with the addition of GO. However, since our systems include a mixture of carbon precursors, the calculation of $L_{a}$ should be considered as a trend. Nevertheless, this result shows the beneficial contribution of GO to promote the formation of more ordered carbon materials [45].

Similar phenomena were confirmed by XRD measurements (Fig. 5.b). The XRD patterns show a diffraction peak located at $2 \theta=26^{\circ}$, corresponding to the (002) crystallographic planes of the graphitic structure. This peak suggests a reorganization of the microstructure after carbonization with transformation of the $\mathrm{sp}^{3}$ carbon from GO [18] and lignin [28] into $\mathrm{sp}^{2}$ carbon. The average interlayer spacing $d_{(002)}$, the stacking size of the crystalline domains $L_{c(002)}$, and the number of graphitic planes per domain were evaluated using the Bragg and Scherrer equations [46]. The results are reported in Table 1 . The $d_{(002)}$ distance appears to be constant for all initial GO/lignin ratios. However, increasing the initial amount of lignin in 3D-printed structures results in broader (002) peaks. Thus, the crystallite dimension $L_{c(002)}$ and the number of graphitic planes per crystallite decrease with the lignin fraction. Lignin therefore tends to make the carbon materials more disordered. Nevertheless, the presently investigated composites still have more ordered microstructures than those of carbon materials obtained from pure lignin [28].

\section{Table 1}

Microstructural properties of the carbonized 3D-Printed structures, depending on the initial GO-lignin ink formulation.

\begin{tabular}{|c|c|c|c|c|c|c|}
\hline \multirow{2}{*}{$\begin{array}{l}\mathrm{GO} / \text { lignin ink } \\
\text { formulation }\end{array}$} & \multicolumn{2}{|c|}{ Raman } & \multicolumn{4}{|c|}{ XRD } \\
\hline & $\begin{array}{l}I_{D} / I_{G} \\
\text { Ratio }\end{array}$ & $\begin{array}{c}\text { Crystallite } \\
\text { size } \\
L_{a}[\mathrm{~nm}]\end{array}$ & $2 \theta[\mathrm{deg}]$ & $d_{(002)}[\mathrm{nm}]$ & $\begin{array}{l}\text { Crystallite stacking } \\
\text { size } L_{c}[\mathrm{~nm}]\end{array}$ & $L_{c} / d_{1002}$ \\
\hline $15 / 85$ & 1.03 & 11.7 & 25.42 & 0.333 & 2.8 & 8.4 \\
\hline $30 / 70$ & 1.09 & 12.4 & 25.3 & 0.332 & 3.1 & 9.2 \\
\hline $50 / 50$ & 1.15 & 13.1 & 25.48 & 0.334 & 4.4 & 13.2 \\
\hline $70 / 30$ & 1.26 & 14.3 & 25.52 & 0.335 & 6.2 & 18.6 \\
\hline $100 / 0$ & 1.41 & 16 & 26.05 & 0.342 & 11.2 & 32.7 \\
\hline
\end{tabular}

The microstructural orientation of the carbonized structures was evaluated for different GO/lignin ratios using 2D-WAXS azimuthal intensity distributions of the (002) reflection (Fig. 5.c). For each GO/lignin ratio, two intensity peaks appear at $90^{\circ}$ and $270^{\circ}$. These peaks reveal a preferential horizontal orientation of the graphitic planes. The initial orientation of 
the microstructure resulting from the extrusion is retained after carbonization, the GO flakes potentially acting as a template for the graphitic structure [47]. The horizontal intensity $\left(I_{H(002)}\right)$ at $90^{\circ}$ and $270^{\circ}$ and the vertical intensity $\left(I_{V(002)}\right)$ at $180^{\circ}$ of the azimuthal intensity distribution depend on the initial GO/lignin ratio. From these intensities, we define an order parameter $(\eta)$, according to the following equation [48].

$$
\eta=\frac{I_{H(002)}-I_{V(002)}}{I_{H(002)}+I_{V(002)}}
$$

This order parameter allows a quantification of the ordering of the different samples. If the graphitic planes have no preferential orientation, then $\eta=0$, while $\eta=1$ corresponds to complete horizontal alignment. The order parameter changes from 0.27 to 0.9 with the increase of the GO fraction (Fig. 5.d). Thus, the addition of GO in carbonized lignin-based system promotes microstructural ordering.

The microstructural organization and arrangement of the carbonized 3D-printed objects as a function of the initial GO/lignin ratio were also evaluated from SEM images (Fig. 6). The initial alveolar microstructure disappears (see Fig. 3-d.1) and tends to form domains that are more compact as the initial amount of lignin increases. In addition, the preferential horizontal order of the microstructure seems to decrease with the amount of lignin. The internal porosity of the 3D-printed lignin-GO structures is therefore reduced after annealing at $1000^{\circ} \mathrm{C}$. This behavior can be linked to the increase in carbon yield due to the higher amount of lignin in the initial material.
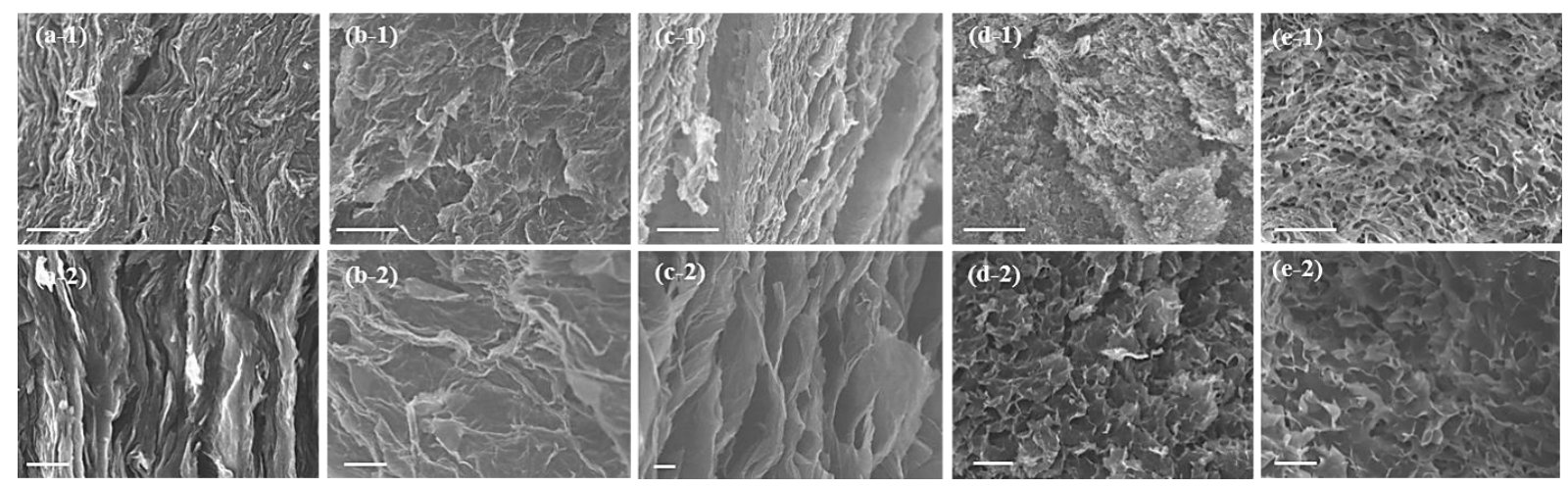

Fig 6. SEM images of the internal microstructure of the carbonized 3D-printed structures for various initial GO/lignin ratios: (a) 15/85, (b) 30/70, (c) 50/50, (d) 70/30, (e) 100/0. Scale bars: (1) $50 \mu \mathrm{m}$, (2) $5 \mu \mathrm{m}$. 


\subsection{Physical Properties of the Carbonized 3D-Printed Lignin-GO Structures}

The density of carbonized 3D-printed structures depends on the initial GO/lignin ratio (Fig. 7.a). The skeletal density of the carbon material lies between 1.7 and $1.8 \mathrm{~g} . \mathrm{cm}^{-3}$ for GO/lignin ratios between $15 / 85$ and $50 / 50$. This density drops to $1.2 \mathrm{~g} . \mathrm{cm}^{-3}$ for a pure GO system. The bulk density follows the same trends as the skeletal density for materials mainly composed of lignin. Thus, the percentage of porosity is relatively low. This high density is due to the high carbon yield of lignin submitted to pyrolysis. However, as the amount of GO increases, the percentage of porosity increases significantly until it reaches $90 \%$ for pure GO structures.

The densification of the material by addition of lignin also results in the evolution of the electrical conductivity as a function of the initial lignin-GO composition (Fig. 7.b). The electrical conductivity displays an optimal value depending on the fraction of GO (Table 2). This behavior can be understood by considering the density and the graphitic ordering of the systems. The conductivity is expected to increase with the density of the material. Nevertheless, it is also expected to increase with graphitic ordering [45,49]. The influence of GO has therefore two opposite effects. For low amounts of GO, electrical conductivity increases because of better ordering with addition of GO. Further addition leads to decrease because of lower density not compensated by graphitic ordering. These two competing mechanisms explain the optimal conductivity observed for a given amount of GO. The electrical properties can be thus finely tuned by changing the composition of the inks.

The mechanical properties are characterized by their compressive stress-strain tests (Fig. 7.c). The cylindrical samples are compressed until they collapse. The Young's modulus and the compressive strength of the 3D-printed objects increase significantly with the addition of lignin (Fig. 7.d). However, the materials become also more brittle with a reduction in the maximum compressive strain. This behavior can be associated with the increase in density and the reduction of porosity for the highest levels of carbonized lignin (Table 2). In the present system, lignin appears as a mechanical reinforcement of the carbonized 3D-printed lignin-GO materials. 

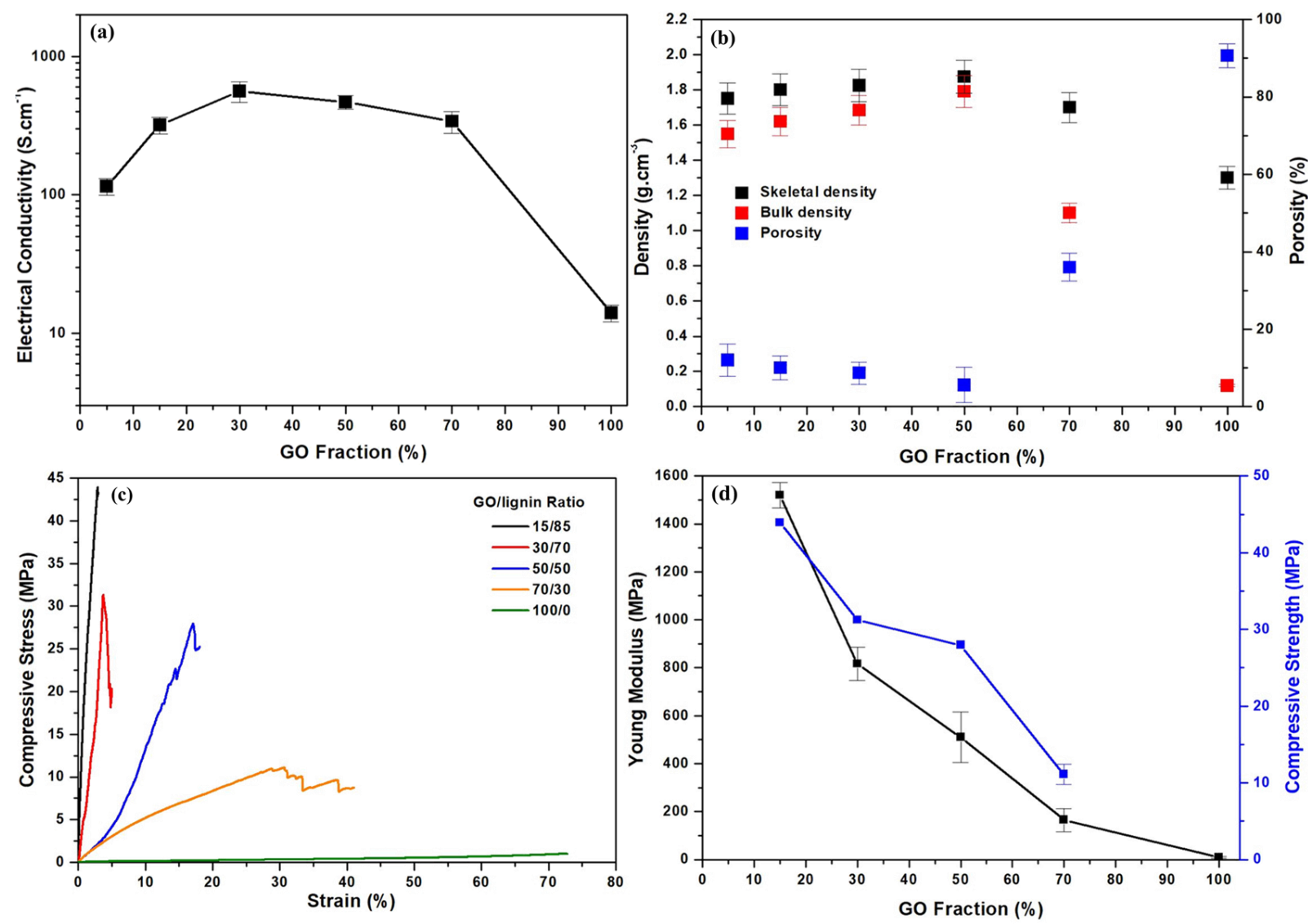

Fig 7. Evolution of (a) electrical conductivity, (b) density, porosity, and (d) mechanical properties depending on initial GO fraction. (c) Stress-strain curves for compression tests of the carbonized 3D-printed structures for various initial GO/lignin ratios.

The total porosity of these $3 \mathrm{D}$-printed materials is thus quite high, as soon as enough GO is present in the formulation of the inks, as shown in Fig. 7.b. However, the voids inside the materials themselves should be separated from the intrinsic porosity of the carbon backbone, the latter being measured through adsorption experiments. From the nitrogen adsorption isotherms obtained at $196^{\circ} \mathrm{C}$, the surface areas were first calculated with the BET method, which is one of the most widely used in the literature. The corresponding results are given in Table 2. The pore size distributions (PSDs) were also obtained by applying the 2D-NLDFTHS method, which provides more accurate results by combining $\mathrm{N}_{2}$ and $\mathrm{CO}_{2}$ adsorption data simultaneously [50-51]. By integration of the PSDs over the entire range of pore sizes [52] (not shown), the $S_{N L D F T}$ surface areas and the total pore volumes could be calculated and are also presented in Table 2.

The fact that the BET surface area is much lower than that obtained by NLDFT demonstrates the presence of extremely narrow pores, in which nitrogen used as a probe molecule cannot efficiently diffuse. Therefore, only NLDFT values should be taken into account. But whatever 
the values of surface area considered, all are quite low, as are the corresponding pore volumes. These results are logical, since the materials were simply pyrolyzed and not subjected to any activation process. Table 2 shows that, on average, more GO promotes the intrinsic porosity of the carbon backbone, which might be easily developed further by any activation process. In this way, structured activated carbons potentially useful for adsorption purposes in reactors, or for serving as catalyst supports, would be achieved.

\section{Table 2}

Physical properties of the carbonized 3D-Printed structures, depending on the initial GOlignin composition.

\begin{tabular}{cccccc}
\hline $\begin{array}{c}\text { GO/lignin } \\
\text { ink } \\
\text { formulation }\end{array}$ & $\begin{array}{c}\text { Bulk density } \\
{\left[\mathrm{g} \cdot \mathrm{cm}^{-3}\right]}\end{array}$ & $\begin{array}{c}\text { BET surface area } \\
{\left[\mathrm{m}^{2} \cdot \mathrm{g}^{-1}\right]}\end{array}$ & $\begin{array}{c}\text { NLDFT surface area } \\
{\left[\mathrm{m}^{2} \cdot \mathrm{g}^{-1}\right]}\end{array}$ & $\begin{array}{c}\text { Pore volume } \\
{\left[\mathrm{cm}^{3} \cdot \mathrm{g}^{-1}\right]}\end{array}$ & $\begin{array}{c}\text { Conductivity } \\
{\left[\mathrm{S} . \mathrm{cm}^{-1}\right]}\end{array}$ \\
\hline $15 / 85$ & 1.62 & 4 & 47 & 0.024 & 320 \\
$30 / 70$ & 1.69 & 7 & 67 & 0.032 & 560.5 \\
$50 / 50$ & 1.8 & 12 & 88 & 0.06 & 468 \\
$70 / 30$ & 1.1 & 18 & 63 & 0.05 & 340 \\
$100 / 0$ & 0.2 & 49 & 92 & 0.12 & 14 \\
\hline
\end{tabular}

The combination of lignin and GO allows therefore the 3D printing of carbon structures with tunable textural, mechanical and electrical properties. The present materials can behave either as highly compressible and porous carbon aerogels, or as stiffer materials with improved mechanical and transport properties.

\section{Conclusion}

We have demonstrated a strategy for developing 3D composite graphitic carbon materials by direct-ink writing. A new ink formulation based on a lignin-GO mixture was developed. The viscoelastic properties of the inks were found to be suitable for making uniform 3D-printed objects. The alignment of the GO flakes was controlled during the ink extrusion. Pure GO inks lead to the elaboration of highly compressible aerogel-like carbon structures. Although their microstructure is well ordered, their electrical conductivity remains relatively low due to high porosity. The presence of lignin in the precursor material allows printing denser structures. Although less ordered at the microscopic scale, these denser structures have improved electrical conductivity and mechanical resistance. Actually, the mechanical and electrical properties can be finely tuned by playing with the antagonistic effects of graphitic 
ordering and porosity when changing the GO to lignin ratio. The possibility of tuning properties makes the present approach promising for a broader range of applications.

\section{Acknowledgments}

We acknowledge the financial support from the IRT Jules Verne (French Institute in Research and Technology in Advanced Manufacturing Technologies for Composite, Metallic and Hybrid Structures).

\section{REFERENCES}

[1] X. Huang, Z. Yin, S. Wu, X. Qi, Q. He, Q. Zhang, Q. Yan, F. Boey, H. Zhang, Graphene-based materials: Synthesis, characterization, properties, and applications, Small. 7 (2011) 1876-1902

[2] Y. Zhu, S. Murali, W. Cai, X. Li, J.W. Suk, J.R. Potts, R.S. Ruoff, Graphene and graphene oxide: Synthesis, properties, and applications, Adv. Mater. 22 (2010) 39063924.

[3] G. Reina, J.M. González-Domínguez, A. Criado, E. Vázquez, A. Bianco, M. Prato, Promises, facts and challenges for graphene in biomedical applications, Chem. Soc. Rev. 46 (2017) 4400-4416.

[4] H. Wang, Y. Liu, M. Li, H. Huang, H.M. Xu, R.J. Hong, H. Shen, Leveling graphene sheet through electrospinning and its conductivity, RSC Adv. 5 (2015) 42174-42177.

[5] C. Lee, X. Wei, J.W. Kysar, J. Hone, Measurement of the Elastic Properties and Intrinsic Strength of Monolayer Graphene, Science. 321 (2008) 385-388.

[6] J.S. Bunch, S.S. Verbridge, J.S. Alden, A.M. Van Der Zande, J.M. Parpia, H.G. Craighead, P.L. Mceuen, Impermeable Atomic Membranes from Graphene Sheets, Nano Lett. 8 (2008) 2458-2462.

[7] Z. Xu, C. Gao, Graphene fiber: A new trend in carbon fibers, Mater. Today. 18 (2015) $480-492$.

[8] Z. Wang, H. Gao, Q. Zhang, Y. Liu, J. Chen, Z. Guo, Recent Advances in 3D Graphene Architectures and Their Composites for Energy Storage Applications, Small. 15 (2019) 1-21.

[9] X. Zhou, X. Zhu, X. Liu, Y. Xu, Y. Liu, Z. Dai, J. Bao, Ultralong cycle life sodium-ion battery anodes using a graphene-templated carbon hybrid, J. Phys. Chem. C. 118 (2014) 22426-22431.

[10] Q. Wang, X. Zhu, Y. Liu, Y. Fang, X. Zhou, J. Bao, Rice husk-derived hard carbons as high-performance anode materials for sodium-ion batteries, Carbon. 127 (2018) 658666. 
[11] X. Ge, S. Liu, M. Qiao, Y. Du, Y. Li, J. Bao, X. Zhou, Enabling Superior Electrochemical Properties for Highly Efficient Potassium Storage by Impregnating Ultrafine Sb Nanocrystals within Nanochannel-Containing Carbon Nanofibers, Angew. Chemie - Int. Ed. 58 (2019) 14578-14583.

[12] G. Xin, W. Zhu, Y. Deng, J. Cheng, L.T. Zhang, A.J. Chung, S. De, J. Lian, Microfluidics-enabled orientation and microstructure control of macroscopic graphene fibres, Nat. Nanotechnol. 14 (2019) 168-175.

[13] C. Xiong, Q. Yang, W. Dang, M. Li, B. Li, J. Su, Y. Liu, W. Zhao, C. Duan, L. Dai, Y. $\mathrm{Xu}$, Y. Ni, Fabrication of eco-friendly carbon microtubes @ nitrogen-doped reduced graphene oxide hybrid as an excellent carbonaceous scaffold to load $\mathrm{MnO} 2$ nanowall (PANI nanorod) as bifunctional material for high-performance supercapacitor and oxygen reduction reaction catalyst, J. Power Sources. 447 (2020) 227387.

[14] M.R. Hartings, Z. Ahmed, Chemistry from 3D printed objects, Nat. Rev. Chem. 3 (2019) 305-314.

[15] R.L. Truby, J.A. Lewis, Printing soft matter in three dimensions, Nature. 540 (2016) 371-378.

[16] W. Fang, S. Yang, X.-L. Wang, T.-Q. Yuan, R.-C. Sun, Manufacture and application of lignin-based carbon fibers (LCFs) and lignin-based carbon nanofibers (LCNFs), Green Chem. 19 (2017) 1794-1827.

[17] S. Pei, H.M. Cheng, The reduction of graphene oxide, Carbon. 50 (2012) 3210-3228.

[18] C. Zhu, T.Y.J. Han, E.B. Duoss, A.M. Golobic, J.D. Kuntz, C.M. Spadaccini, M.A. Worsley, Highly compressible 3D periodic graphene aerogel microlattices, Nat. Commun. 6 (2015) 1-8.

[19] J. Zhong, G. Zhou, P. He, Z. Yang, 3D printing strong and conductive geo-polymer nanocomposite structures modi fi ed by graphene oxide, Carbon. 117 (2017) 421-426.

[20] K. Fu, Y. Wang, C. Yan, Y. Yao, Y. Chen, J. Dai, S. Lacey, Y. Wang, J. Wan, T. Li, Z. Wang, Y. Xu, L. Hu, Graphene Oxide-Based Electrode Inks for 3D-Printed LithiumIon Batteries, Adv. Mater. 28 (2016) 2587-2594.

[21] Y. Yao, K.K. Fu, C. Yan, J. Dai, Y. Chen, Y. Wang, B. Zhang, E. Hitz, L. Hu, ThreeDimensional Printable High-Temperature and High-Rate Heaters, ACS Nano. 10 (2016) 5272-5279.

[22] S. Naficy, R. Jalili, S.H. Aboutalebi, R.A. Gorkin, K. Konstantinov, P.C. Innis, G.M. Spinks, P. Poulin, G.G. Wallace, Graphene oxide dispersions: Tuning rheology to enable fabrication, Mater. Horizons. 1 (2014) 326-331.

[23] A. M'Barki, L. Bocquet, A. Stevenson, Linking Rheology and Printability for Dense and Strong Ceramics by Direct Ink Writing, Sci. Rep. 7 (2017) 1-10.

[24] J.A. Lewis, G.M. Gratson, Direct writing in three dimensions, Mater. Today. 7 (2004) $32-39$. 
[25] M.K. Hausmann, P.A. Rühs, G. Siqueira, J. Läuger, R. Libanori, T. Zimmermann, A.R. Studart, Dynamics of Cellulose Nanocrystal Alignment during 3D Printing, ACS Nano. 12 (2018) 6926-6937.

[26] Y. Jiang, Z. Xu, T. Huang, Y. Liu, F. Guo, J. Xi, W. Gao, Direct 3D Printing of Ultralight Graphene Oxide Aerogel Microlattices, Adv. Funct. Mater 1707024 (2018) $1-8$.

[27] C.M. Doherty, W. O. S.; Mousavioun, P.; Fellows, Value-adding to cellulosic ethanol: Lignin polymers., Ind. Crops Prod. 33 (2011) 259-276.

[28] J. Roman, W. Neri, A. Derré, P. Poulin, Electrospun lignin-based twisted carbon nanofibers for potential microelectrodes applications, Carbon. 145 (2019) 556-564.

[29] D.A. Baker, T.G. Rials, Recent advances in low-cost carbon fiber manufacture from lignin, J. Appl. Polym. Sci. 130 (2013) 713-728.

[30] Y. Shao, C. Guizani, P. Grosseau, D. Chaussy, D. Beneventi, Use of lignocellulosic materials and 3D printing for the development of structured monolithic carbon materials, Compos. Part B. 149 (2018) 206-215.

[31] Y. Shao, D. Chaussy, P. Grosseau, D. Beneventi, Use of Microfibrillated Cellulose/Lignosulfonate Blends as Carbon Precursors: Impact of Hydrogel Rheology on 3D Printing, Ind. Eng. Chem. Res. 54 (2015) 10575-10582.

[32] W. Xu, X. Wang, N. Sandler, S. Willför, C. Xu, Three-Dimensional Printing of WoodDerived Biopolymers: A Review Focused on Biomedical Applications, ACS Sustain. Chem. Eng. 6 (2018) 5663-5680.

[33] J.A. Lewis, Direct ink writing of 3D functional materials, Adv. Funct. Mater. 16 (2006) 2193-2204.

[34] C. Vallés, R.J. Young, D.J. Lomax, I.A. Kinloch, The rheological behaviour of concentrated dispersions of graphene oxide, J. Mater. Sci. 49 (2014) 6311-6320.

[35] G. Siqueira, D. Kokkinis, R. Libanori, M.K. Hausmann, A.S. Gladman, A. Neels, P. Tingaut, T. Zimmermann, J.A. Lewis, A.R. Studart, Cellulose Nanocrystal Inks for 3D Printing of Textured Cellular Architectures, Adv. Funct. Mater. 1604619 (2017).

[36] Z.Xu and C. Gao, Aqueous Liquid Crystals of Graphene Oxide, ACS Nano. 5 (2011) 2908-2915.

[37] L. Qiu, J.Z. Liu, S.L.Y. Chang, Y. Wu, D. Li, Biomimetic superelastic graphene-based cellular monoliths, Nat. Commun. 3 (2012) 1-7.

[38] X. Gao, J. Jang, S. Nagase, Hydrazine and Thermal Reduction of Graphene Oxide : Reaction Mechanisms and Design, J. Phys. Chem. C. (2010) 1-81.

[39] J.L. Braun, K.M. Holtman, J.F. Kadla, Lignin-based carbon fibers: Oxidative thermostabilization of kraft lignin, Carbon. 43 (2005) 385-394.

[40] I. Brodin, M. Ernstsson, G. Gellerstedt, E. Sjöholm, Oxidative stabilisation of kraft lignin for carbon fibre production, Holzforschung. 66 (2012) 141-147. 
[41] M. Wang, L.D. Duong, Y. Ma, Y. Sun, S.Y. Hong, A strategy to synthesize grapheneincorporated lignin polymer composite materials with uniform graphene dispersion and covalently bonded interface engineering, Korea-Australia Rheology J. 29 (2017) 207213.

[42] K.N. Kudin, B. Ozbas, H.C. Schniepp, R.K. Prud'homme, I.A. Aksay, R. Car, Raman spectra of graphite oxide and functionalized graphene sheets, Nano Lett. 8 (2008) 3641.

[43] I. Dallmeyer, L.T. Lin, Y. Li, F. Ko, J.F. Kadla, Preparation and characterization of interconnected, Kraft lignin-based carbon fibrous materials by electrospinning, Macromol. Mater. Eng. 299 (2014) 540-551.

[44] A.C. Ferrari, J. Robertson, Interpretation of Raman spectra of disordrred and amorphous carbon, Phys. Rev. B. 61 (2000) 14295.

[45] M. Föllmer, S. Jestin, W. Neri, A. Derré, A. Bentaleb, C. Mercader, P. Poulin, Structuration of lignin-graphene oxide based carbon materials through liquid crystallinity, Carbon. 149 (2019) 297-306.

[46] C. Kim, S.H. Park, J.I. Cho, D.Y. Lee, T.J. Park, W.J. Lee, K.S. Yang, Raman spectroscopic evaluation of polyacrylonitrile-based carbon nanofibers prepared by electrospinning, J. Raman Spectrosc. 35 (2004) 928-933.

[47] D. Papkov, A. Goponenko, O.C. Compton, Z. An, A. Moravsky, X.Z. Li, S.T. Nguyen, Y.A. Dzenis, Improved graphitic structure of continuous carbon nanofibers via graphene oxide templating, Adv. Funct. Mater. 23 (2013) 5763-5770.

[48] M. Pinault, D. Porterat, C. Mocuta, E. Elkaim, M. Mayne-1, P. Launois, I. Catalytic, A. Ccvd, Growth of aligned multi-walled carbon nanotubes: First in situ and time-resolved X-ray diffraction analysis, Phys. Status Solidi B. 248 (2011) 2449-2453.

[49] K. Miyasaka, K. Watanabe, E. Jojima, H. Aida, M. Sumita, K. Ishikawa, Electrical conductivity of carbon-polymer composites as a function of carbon content, J. Mater. Sci. 17 (1982) 1610-1616.

[50] C. Ania, J.B. Parra, C. Cook, Dual gas analysis of microporous carbons using 2DNLDFT heterogeneous surface model and combined adsorption data of $\mathrm{N}_{2}$ and $\mathrm{CO}_{2}$, Carbon. 91 (2015) 1610-1616.

[51] J. Jagiello, J. Kenvin, A. Celzard, V. Fierro, Enhanced resolution of ultra micropore size determination of biochars and activated carbons by dual gas analysis using $\mathrm{N}_{2}$ and $\mathrm{CO}_{2}$ with 2D-NLDFT adsorption models, Carbon. 144 (2019) 206-215.

[52] T.A. Centeno, F. Stoeckli, The assessment of the surface areas in porous carbons by two model-independent techniques, the DR equation and DFT, Carbon. 48 (2010) 2478-2486. 